
\title{
25 Research Square \\ Pancreatic neck thickness: A possible key to stump closure technique selection after distal pancreatectomy
}

Andrej Nikov ( $\square$ andrej.nikov@gmail.com )

Ustredni vojenska nemocnice - Vojenska fakultni nemocnice Praha https://orcid.org/0000-0003-36501117

\section{Pavel Záruba}

Ustredni vojenska nemocnice - Vojenska fakultni nemocnice Praha

\section{František Bělina}

Ustredni vojenska nemocnice - Vojenska fakultni nemocnice Praha

\section{Miroslav Ryska}

Ustredni vojenska nemocnice - Vojenska fakultni nemocnice Praha

\section{Research article}

Keywords: distal pancreatectomy, pancreatic stump closure, postoperative pancreatic fistula

Posted Date: August 13th, 2019

DOI: https://doi.org/10.21203/rs.2.12754/v1

License: (9) (1) This work is licensed under a Creative Commons Attribution 4.0 International License. Read Full License

Version of Record: A version of this preprint was published at HPB on September 1st, 2018. See the published version at https://doi.org/10.1016/j.hpb.2018.06.2128. 


\section{Abstract}

Background To date, no stump closure technique has been shown to be superior in lowering the risk of postoperative pancreatic fistula (POPF) after pancreatectomy. The aims our study were to investigate the possibility to influence POPF risk by selection of stump closure technique according to pancreatic parenchyma thickness and to establish a thickness cut-off value for selection of a hand-sewn and stapled closure technique. Methods A retrospective analysis of consecutive patients who underwent distal pancreatectomy at a single centre was performed. Anatomical determination of the transection site (pancreatic neck, body, or tail) was based on operative report and postoperative follow-up computed tomography (CT), with the thickness measured on the most recent CT image before surgery. Patients were classified by the thickness of the transection site, and sub-classified according to stump closure technique. POPF incidence, morbidity, mortality, and baseline-characteristics were investigated between groups. Results Among the 115 cases included in the analysis, the incidence of POPF was $33 \%$, with no difference between stapled (29.9\%) and hand-sewn (37.5\%) closure techniques $(p=0.426)$, regardless of transection site thickness. Among those with a transection site $<13 \mathrm{~mm}$, the incidence of POPF was $4.6 \%$ in the stapler subgroup versus $45.5 \%$ in the hand-sewn subgroup $(p=0.0002)$. Among patients with a transection site $\geq 13 \mathrm{~mm}$, the incidence of POPF was $75 \%$ in the stapler subgroup versus $30.8 \%$ in the hand-sewn subgroup $(p=0.007)$. Conclusions Transection in the pancreatic neck, stapler closure of thin parenchyma, and hand-sewn closure of thick parenchyma were associated with significantly lower risk of POPF.

\section{Background}

Postoperative pancreatic fistula (POPF) is common complication of distal pancreatectomy, occurring in up to $61 \%$ of patients [1]. POPF is the main cause of morbidity after distal pancreatectomy, increases the healthcare costs, and further increases the risk of potentially fatal complications, including sepsis, vascular events, and haemorrhage [2]. Although advances in surgical technique and peri-operative care have decreased the mortality rate after distal pancreatectomy to $<2 \%$, the incidence of POPF has remained unchanged [3].

Stapled and hand-sewn closure of pancreatic stump are two basic techniques, with many derived modifications having been developed. Several meta-analyses and randomized controlled trials (RCTs), however, did not prove efficiency of any measure purposed to reduce the risk of POPF, including stump closure technique (stapler versus hand-sewn or compared to pancreatojejunostomy, etc.) or stump reinforcement (fibrin sealant, autologous patches) [4-11]. This body of high-level evidence has contributed to a sense of futility of efforts to reduce the incidence of POPF. However, technical factors with proven impact on POPF risk, such as pancreatic parenchyma thickness, were omitted in the design of these RCTs, which focused on stump closure technique. Furthermore, Eguchi et al. suggested that thickness at the transection site can further influence selection of the stump closure technique [12]. Therefore, conclusions of these RCTs that focused on stump closure technique might be of limited utility as each closure technique could be suitable for specific target group. Even if there are suggestions of 
major disadvantages of stapled closure of thick pancreatic stump, evidence supporting a superiority of stapled closure of thin stump and hand-sewn closure of thick stump is still lacking.

To address this gap in current evidence, the aims of our study were to investigate the possibility to influence POPF risk by selection of stump closure technique according to the pancreatic parenchyma thickness, and to establish a thickness cut-off value for selection between the hand-sewn and stapled closure techniques.

\section{Methods}

This study was approved by Institutional Review board of Military University Hospital Prague and informed consent was obtained from all patients. A retrospective analysis of all consecutive patients undergoing distal pancreatectomy for all indications at a single centre, between January 2011 and December 2017, was performed. Extended distal pancreatectomies (according to International Study Group on Pancreatic Surgery (ISGPS) definition [13]) were also included. Only two pancreatic stump closure techniques were used - stapler closure and scalpel transection with hand-sewn closure. Choice of stump closure technique was left to the surgeon to decide based on personal preference. Stapler closure was performed using an Echelon $60 \mathrm{~mm}$ system, with gold cartridge (Ethicon Endo-Surgery, Cincinnati, USA), or EndoGIA $60 \mathrm{~mm}$ with violet cartridge (Covidien, Medtronic, Minneapolis, USA). For stapler closures, great emphasis was placed on a slow, gradual, and interrupted increase of stapler jaws pressure and extension of pre-firing time to 2 min to avoid parenchyma crushing during stapling. Hand-sewn closure of the pancreatic stump after scalpel transection was performed using a row of interrupted figureof-eight polydioxanone 3/0 - 4/0 sutures. Two Penrose drains, without suction, were left in place. Prophylactic octreotide was not administered.

Demographic and patient data (age, sex, body-mass index, albumin level, histopathological diagnosis), intraoperative variables (stump closure technique, spleen non/preservation, operating time, blood-loss) and outcomes were obtained from prospectively maintained database of pancreatic resections. Outcomes were: rate of clinically relevant POPF (CR-POPF; grade B and C) and biochemical leak $(\mathrm{BL})$ rate - defined and classified according to the criteria of the updated ISGPS Definition [14]; the 90 day mortality, overall morbidity (Clavien-Dindo grade II and more [15]), severe complications rate (Clavien-Dindo grade $\geq \mathrm{Illa}$ ), surgical site infection (SSI), need of re-laparotomy and length of hospital stay (LOS).

The site of parenchyma transection was anatomically determined as the pancreatic neck or body / tail, based on operative report and postoperative follow-up computed tomography (CT) scans. Parenchymal thickness at the site of transection (anterior to posterior distance on axial scans - Fig.1.) was measured on the most recent CT scans before surgery. Cut-off values of transection site thickness sufficiently predicting pancreatic leak (CR-POPF or $\mathrm{BL}$ ) were established by receiver operating characteristic (ROC) curve analysis. Patients with transection site thickness equal or above the cut-off were included in the thick pancreas group, with patients below the cut-off forming the thin pancreas group. Baseline 
characteristics and outcomes of stump closure were compared in the general cohort (regardless of parenchyma thickness) and then separately for the thin and thick pancreas subgroup.

Continuous variables were expressed as median value and range, between-group differences tested using the Mann-Whitney U-test. Categorical data were described by the percentage, with between-group comparisons tested using Fisher's exact test or chi-squared test, as appropriate. Outcomes were expressed as odds-ratio (OR) with 95\% confidence-interval (Cl). Univariate analysis was performed to establish factors associated with pancreatic leak (CR-POPF or BL) and multivariate logistic regression analysis was performed to determine independent predictors of pancreatic leak. All statistical tests were two-sided, with the level of statistical significance set at a $p$-value $<0.05$. All statistical analyses were performed using StatsDirect software, Version 3.1.20 (Cambridge, UK).

\section{Results}

\section{Patient data and perioperative characteristics}

One hundred and fifteen patients were enrolled into our retrospective study. Four distal pancreatectomies were performed laparoscopically, and 111 as an open procedure. Their baseline characteristics and perioperative variables are shown in Table 1. There were no significant differences between patients' demographics between the groups, except for the male-to-female ratio. As sex does not exert a confounding influence on stump closure selection or outcomes [16], propensity matching was not performed. Even if procedures with stapled pancreatic stump tended to have shorter operative time than procedures using a hand-sewn closing technique (median time 180 versus 210 min., $p=0.037$ ), other perioperative variables did not differ among stump closure groups.

The distribution of pancreatic thickness as a function of pancreatic leak (CR-POPF or BL) occurrence and stump closure technique is shown in Fig.2. ROC analysis for pancreatic transection site thickness to predict pancreatic leak in both stapled and hand-sewn groups established the same optimal cut-off thickness value for both techniques, $13 \mathrm{~mm}$ (Fig.3). Therefore, the $13 \mathrm{~mm}$ cut-off was used to divide patients into the thin and thick pancreas group and to investigate the outcomes of each stump closure technique according to pancreatic tissue thickness.

\section{Outcomes}

Outcomes of this sub-group analysis are depicted in Table 2. The CR-POPF rate for the entire cohort was $33 \%$, and did not differ between the stapler and hand-sewn group, when investigated irrespective of pancreatic thickness $(\mathrm{OR}, 0.71 ; 95 \% \mathrm{Cl}, 0.32-1.57 ; \mathrm{p}=0.426)$. Closure of a transection of a thin pancreas using a stapler was associated with a lower risk of CR-POPF than hand-sewn closure $(\mathrm{OR}, 0.06 ; 95 \% \mathrm{Cl}$, $0.006-0.34 ; p=0.0002)$. Vice versa, stapled closure of a thick pancreas was associated with significantly worse outcomes than with a hand-sewn closure (CR-POPF OR, 6.75; 95\% Cl, 1.7-28.4; $p=0.0023$ ). 
The overall 90-day mortality rate for the entire cohort was $2.6 \%$ (3/115 patients), with an extended resection being associated with all cases of mortality $(\mathrm{OR} ; 95 \% \mathrm{Cl}, 2.96$ - infinity; $\mathrm{p}=0.0046)$, rather than stump closure technique $(\mathrm{OR}, 0.35 ; 95 \% \mathrm{Cl}, 0.006-6.9 ; \mathrm{p}=0.446)$. All three patients died after extended resection. All deaths were associated with $\mathrm{POPF}$, followed by gastrointestinal anastomosis leakage in both cases of multivisceral resections or thrombosis of vascular reconstruction in the other case. The mortality rate was not significantly different between the thin and thick pancreas groups for either stapled or hand-sewn stump closures.

The morbidity after stapled and hand-sewn group, irrespective of parenchyma thickness, was similar (OR, $0.67 ; 95 \% \mathrm{Cl}, 0.28-1.57 ; \mathrm{p}=0.33$ ). A difference between the two closures was, however, identified between the two thickness subgroups. In the thin pancreas group, the OR of morbidity was 0.22 $(95 \% \mathrm{Cl}, 0.06-0.77 ; \mathrm{p}=0.008)$, whereas is in the thick group, all patients who underwent a stapled closure developed complications (OR $95 \% \mathrm{Cl}, 3.04$ - infinity; $p=0.0012$ ). The rate of severe complications did not differ neither in the overall cohort $(\mathrm{OR}, 0.85 ; 95 \% \mathrm{Cl}, 0.36-2.04 ; \mathrm{p}=0.695)$ nor in both thickness - subgroups (thin OR, 0.34; $95 \% \mathrm{Cl}, 0.09-1.32 ; \mathrm{p}=0.086$; thick $\mathrm{OR}, 2.66 ; 95 \% \mathrm{Cl}, 0.73$ 9.95; $p=0.107$, respectively). Overall, the rate of POPF and morbidity, as well as the LOS was significantly lower when a thin pancreas was stapled and a thick hand-sewn.

Univariate analysis of risk factors identified an association between pancreatic leak (CR-POPF or $\mathrm{BL}$ ) risk and a parenchyma thickness at the site of transection $\geq 13 \mathrm{~mm}$ and transection beyond the pancreatic neck (Table 3.). On multivariate analysis, only a parenchyma thickness $\geq 13 \mathrm{~mm}$ was retained as an independent predictor of pancreatic leak $(\mathrm{OR}, 3.85 ; 95 \% \mathrm{Cl}, 1.26-11.8 ; \mathrm{p}=0.018)$.

\section{Discussion}

The main findings of our study were as follows. (1) As published by others [3], the risk of POPF did not differ between stapler and hand-sewn stump closure, irrespective of the parenchyma thickness. (2) The thickness of the pancreatic parenchyma at the site of transection was an independent predictor of POPF, regardless of stump closure technique, as reported in a previous paper [12]. (3) The risk of POPF could be influenced by stump closure technique selected according to parenchyma thickness. (4) The optimal cutoff value of parenchyma thickness for selection of stump closure technique was $13 \mathrm{~mm}$. (5) Stapled closure of a pancreatic stump $<13 \mathrm{~mm}$ in thickness was associated with a considerably lower risk of POPF than for a thin stump closed using a hand sewn technique. (6) Hand-sewn closure of a stump $\geq 13$ $\mathrm{mm}$ was associated with substantial risk of POPF, but still significantly lower for a stapled closure of a thick stump. (7) The rate of mortality and severe complications was associated with extended pancreatectomy instead of stump closure technique in both thickness sub-groups.

POPF remains an unresolved problem of distal pancreatectomy due to its frequent occurrence and serious sequelae. Stump closure techniques have been extensively researched as a factor with presumed fundamental importance for POPF risk. In accordance with previous findings [3,6,9], we did not identify a specific difference in POPF outcome between stapler and hand-sewn closure when analysed 
irrespective of transection site thickness. Previous retrospective studies on the influence of pancreatic parenchyma thickness on POPF risk concluded that stapled closure of stumps thicker than $12 \mathrm{~mm}$ as being associated with an unacceptable risk of POPF, with a suggestion that no stapler cartridge can safely seal a stump thicker than $12 \mathrm{~mm}[17,18]$. This conclusion reflects generally known experience with the crushing that is caused by a stapler used with a thick pancreatic parenchyma, with subsequent pancreatic fistula. But none of these previous studies compared different stump closure techniques according to pancreatic thickness and none focused on identifying the optimal closure of thick pancreatic stump. Therefore, observing a difference between stump closure techniques as a function of parenchyma thickness at the site of transection in both the thin and thick subgroups and determining of an optimal thickness cut-off in this retrospective study may be of clinical importance.

Another factor indirectly associated with parenchyma thickness is the anatomical site of transection. Pannegeon et al. concluded that transection beyond the pancreatic neck increases risk of POPF [19]. The pancreatic neck is the thinnest part of pancreas in majority of cases, and therefore, is the most appropriate site of transection from the perspective of POPF risk. A parenchyma thickness of $<13 \mathrm{~mm}$ was strongly related to transection through the pancreatic neck in our study. On the contrary, in the thick pancreas group, a significantly higher proportion of transections where performed through the body or tail, rather than the neck of the pancreas. Our multivariate analysis identified parenchyma thickness was the only independent predictor of POPF, rather than transection beyond the anatomically defined pancreatic neck. Therefore, association between a lower risk of POPF with transection through the neck of the pancreas, in our opinion, results from the coincidence of a small parenchyma thickness at the neck of the pancreas. This could also explain the lower rate of POPF observed after distal pancreatectomies due to pancreatic cancer - with mandatory transection of the pancreas through the neck, as reported by Ecker et al. [16].

The correct technique of stapler parenchyma transection for distal pancreatectomy is quite different than the technique used for the stomach or bowel, with performance of the technique being of critical importance to outcomes. A considerably lower rate of POPF was identified after stapled closure of thin pancreatic stump in our study confirms the importance of gradually increasing pressure on the stapler jaws and using an extended time to perform the procedure, as necessary, rather than adhering to pre-firing time, as first described by Okano et al. and Nakamura et al. [20,21]. Hirashita et al. reported a clinically relevant decrease in POPF rate (grade $B+C$ ) from $42.1 \%$ to $5.3 \%$, caused only by introduction of slow parenchyma compression and a prolongation of the pre-firing time to $10 \mathrm{~min}$ [22]. This is comparable with our results (rate of POPF grade B 4,6\%, grade C $0 \%$ in thin pancreas divided by stapler). Comparison to the clinically relevant POPF rate $43 \%$ reported in stapler arm of the DISPACT trial [6] (where stapler technique was not specified regarding to pre-firing time).

The major limitation that can impact the interpretation of the results of this study is its retrospective design. Although thickness-groups were homogenous with regard to baseline characteristics, an unmeasured confounding factor cannot be ruled out. 


\section{Conclusions}

In conclusion, we identified the following factors as potential targets for reducing the risk of POPF. First, dividing the pancreas at its thinnest part (i.e. in the neck), as much as possible, and selecting the stump closure technique according to its thickness - with stapler closure preferred for a thin parenchyma and hand-sewn closure for a thick one. Strategies focused on different stump management that are based on morphological criteria will need further evaluation in the randomised controlled setting. Whereas the difference between stapler and hand-sewn closure of thin stump seems to be very pronounced according to non-randomised studies, randomisation may face an ethical problem. Even if hand-sewn closure of a thick pancreatic stump results in significantly better outcomes than that with stapler, POPF rate still remains relatively high. Therefore, a randomised controlled trial comparing hand-sewn closure with pancreatojejunostomy may represent an encouraging perspective to solve this problem. Pancreato (gastro)-jejunostomy can be an optimal solution for a thick and hard pancreatic stump, as suggested by Karabicak et. al. [1]. Confirmation of this presumption in a randomised controlled trial is also needed.

\section{Abbreviations}

POPF: postoperative pancreatic fistula; RCTs: randomized controlled trials; ISGPS: International Study Group of Pancreatic Surgery; CR-POPF: clinically relevant POPF; BL: biochemical leak; SSI: surgical site infection; LOS: length of hospital stay; CT: computed tomography; ROC: receiver operating characteristic; OR: odds-ratio; $\mathrm{Cl}$ : confidence interval

\section{Declarations}

\section{Acknowledgements}

Not applicable.

\section{Funding}

This study was financially supported by Institutional programme of Military University Hospital Prague M01012

\section{Availability of data and materials}

Our anonymized pancreatic resection database contains sensible data (e.g. date of surgery), with which certain patients could be identified. According to Czech law and according to the approval of the ethics committee, these data must not be published. Access to the database can be obtained from the corresponding author upon reasonable request.

\section{Authors' contributions}

AN contributed to all aspects of this paper. PZ, FB, and MR contributed to study conception and design, 
collection of data and critical revision of the manuscript. All authors approved the final version of the article.

\section{Competing interests}

The authors declare that they have no competing interests.

\section{Consent for publication}

Written informed consent was obtained from all patients.

\section{Ethics approval and consent to participate}

This study was carried out with approval of the institutional ethics committee (Military University Hospital, 2nd Faculty of Medicine, Charles University in Prague, Czech Republic ). Written informed consent was obtained from the participants.

\section{References}

1. Karabicak I, Satoi S, Yanagimoto H, Yamamoto Y, Yamaki S, Kosaka H, et al. Comparison of surgical outcomes of three different stump closure techniques during distal pancreatectomy. Pancreatology. 2017; 17: 497-503.

2. Fukuda Y, Yamada D, Eguchi H, Iwagami Y, Noda T, Asaoka T, et al. A novel preoperative predictor of pancreatic fistula using computed tomography after distal pancreatectomy with staple closure. Surg Today. 2017; 47: 1180-7.

3. Kollár D, Huszár T, Pohárnok Z, Cselovsjy E, Oláh A. A review of techniques for closure of the pancreatic remnant following distal pancreatectomy. Dig Surg. 2016; 33: 320-8.

4. Frozanpor F, Lundell L, Segersvard R, Arnelo U. The effect of prophylactic transpapillary pancreatic stent insertion on clinically significant leak rate following distal pancreatectomy: results of a prospective controlled clinical trial. Ann Surg. 2012; 255: 1032-6.

5. Suc B, Msika S, Piccinini M, Fourtanier G, Hay JM, Flamant Y, et al. Octreotide in the prevention of intra-abdominal complications following elective pancreatic resection: a prospective, multicenter randomized controlled trial. Arch Surg. 2004; 139: 288-4; discussion 295.

6. Diener MK, Seiler CM, Rossion I, Kleeff J, Glanemann M, Butturini G, et al. Efficacy of stapler versus hand-sewn closure after distal pancreatectomy (DISPACT): a randomised, controlled multicentre trial. Lancet. 2011; 377: 1514-22.

7. Kawai M, Hirono S, Okada K, Sho M, Nakajima Y, Eguchi H, et al. Randomized controlled trial of pancreaticojejunostomy versus stapler closure of the pancreatic stump during distal pancreatectomy to reduce pancreatic fistula. Ann Surg. 2016; 264: 180-7.

8. Montorsi M, Zerbi A, Bassi C, Capussotti L, Coppola R, Sacchi M, et al. Efficacy of an absorbable fibrin sealant patch (TachoSil) after distal pancreatectomy: a multicenter, randomized, controlled 
trial. Ann Surg. 2012; 256: 853-9; discussion 859-60.

9. Oláh A, Issekutz A, Belágyi T, Hajdú N, Romics L. Randomized clinical trial of techniques for closure of the pancreatic remnant following distal pancreatectomy. Br J Surg. 2009; 96: 602-7.

10. Weniger M, D'Haese JG, Crispin A, Angele MK, Werner J, Hartwig W. Autologous but not fibrin sealant patches for stump coverage reduce clinically relevant pancreatic fistula in distal pancreatectomy: A systematic review and meta-analysis. World J Surg. 2016; 40: 2771-81.

11. Hassenpflug M, Hinz U, Strobel O, Volpert J, Knebel P, Diener MK, et al. Teres ligament patch reduces relevant morbidity after distal pancreatectomy (the DISCOVER Randomized Controlled Trial). Ann Surg. 2016; 264: 723-30.

12. Eguchi H, Nagano H, Tanemura M, Takeda Y, Marubashi S, Kobayashi S, et al. A thick pancreas is a risk factor for pancreatic fistula after a distal pancreatectomy: Selection of the closure technique according to the thickness. Dig Surg. 2011; 28: 50-6.

13. Hartwig W, Vollmer CM, Fingerhut A, Yeo CJ, Neoptolemos JP, Adham M, et al. Extended pancreatectomy in pancreatic ductal adenocarcinoma: definition and consensus of the International Study Group for Pancreatic Surgery (ISGPS). Surgery. 2014; 156: 1-14.

14. Bassi C, Marchegiani G, Dervenis C, Sarr M, Hilal MA, Adham M, et al. The 2016 update of the International Study Group (ISGPS) definition and grading of postoperative pancreatic fistula: 11 years after. Surgery. 2017; 161: 584-91.

15. Dindo D, Demartines N, Clavien PA. Classification of surgical complications: a new proposal with evaluation in a cohort of 6336 patients and results of a survey. Ann Surg. 2004; 240: 205-13.

16. Ecker BL, McMillan MT, Allegrini V, Bassi C, Beane JD, Beckman RM, et al. Risk factors and mitigation strategies for pancreatic fistula after distal pancreatectomy: Analysis of 2026 resections from the International, Multi-institutional Distal Pancreatectomy Study Group. Ann Surg. 2017; 1. 10.1097/SLA.0000000000002491.

17. Kawai M, Tani M, Okada K-I, Hirono S, Miyazawa M, Shimizu A, et al. Stump closure of a thick pancreas using stapler closure increases pancreatic fistula after distal pancreatectomy. Am J Surg. 2013; 206: 352-9.

18. Kim H, Jang J-Y, Son D, Lee S, Han y, Shin YC, et al. Optimal stapler cartridge selection according to the thickness of the pancreas in distal pancreatectomy. Medicine. 2016; 95: e4441.

19. Pannegeon V, Pessaux P, Sauvanet A, Kianmanesh R, Beighit J. Pancreatic fistula after distal pancreatectomy: predictive risk factors and value of conservative treatment. Arch Surg. 2006; 141 : 1071-6; discussion 1076.

20. Okano K, Kakinoki K, Suto H, Oshima M, Maeda N, Kashiwagi H, et al. Slow parenchymal flattening technique for distal pancreatectomy using an endopath stapler: simple and safe technical management. Hepatogastroenterol. 2010; 57: 1309-13.

21. Nakamura M, Ueda J, Kohno H, Aly MY, Takahata S, Shimizu S, Tanaka M. Prolonged peri-firing compression with a linear stapler prevents pancreatic fistula in laparoscopic distal pancreatectomy. Surg Endosc. 2011; 25: 867-71. 
22. Hirashita T, Ohta M, Yada K, Tada K, Hiroomi S, Yuichi T, et al. Effect of pre-firing compression on the prevention of pancreatic fistula in distal pancreatectomy. Am J Surg. 2018; 216: 506-10.

\section{Tables}

Table 1. Baseline characteristics of the general cohort and groups according to pancreatic transection site thickness

(patient and demographic data, histopathological diagnosis, perioperative variables) 


\begin{tabular}{|c|c|c|c|c|c|c|c|c|c|}
\hline & \multicolumn{3}{|c|}{$\begin{array}{l}\text { OVERALL } \\
(\mathrm{n}=115)\end{array}$} & \multicolumn{3}{|c|}{$\begin{array}{c}\text { THIN PANCREAS } \\
(\mathrm{n}=65) \\
\end{array}$} & \multicolumn{3}{|c|}{$\begin{array}{l}\text { THICK PANCREAS } \\
(\mathrm{n}=50)\end{array}$} \\
\hline & $\begin{array}{l}\text { stapler } \\
(\mathrm{n}=67)\end{array}$ & $\begin{array}{l}\text { hand- } \\
\text { sewn } \\
(\mathrm{n}=48)\end{array}$ & $\mathrm{P}$ & $\begin{array}{l}\text { stapler } \\
\qquad(\mathrm{n}= \\
43)\end{array}$ & $\begin{array}{c}\text { hand- } \\
\text { sewn } \\
(\mathrm{n}= \\
22)\end{array}$ & $\mathrm{p}$ & $\begin{array}{l}\text { stapler } \\
\qquad(\mathrm{n}= \\
24)\end{array}$ & $\begin{array}{c}\text { hand- } \\
\text { sewn } \\
(\mathrm{n}= \\
26)\end{array}$ & $\mathrm{p}$ \\
\hline Age; median & 60 & 62 & 0.588 & 60 & 69 & 0.082 & 61 & 58 & 0.357 \\
\hline (range) & $(22-78)$ & $(20-79)$ & & $(22-78)$ & (39-78) & & (37-78) & $(20-79)$ & \\
\hline Sex (Male: Female) & $22: 45$ & $26: 22$ & 0.025 & $11: 32$ & $15: 7$ & 0.001 & 11:13 & $11: 15$ & 0.81 \\
\hline BMI $\left(\mathrm{kg} / \mathrm{m}^{2}\right) ;$ median & 25.6 & 26.7 & 0.877 & 24.4 & 25.7 & 0.702 & 24.5 & 27.1 & 0.528 \\
\hline (rc & $\begin{array}{l}(17.1- \\
36.3)\end{array}$ & $\begin{array}{l}(18.7- \\
41.5)\end{array}$ & & $\begin{array}{l}(19.2- \\
36.3)\end{array}$ & $\begin{array}{l}(18.7- \\
30)\end{array}$ & & $\begin{array}{l}(17.1- \\
33.8)\end{array}$ & $\begin{array}{l}(19.9- \\
41.5)\end{array}$ & \\
\hline Albumin $(\mathrm{g} / \mathrm{l})$; median & 43 & 42 & 0.133 & 42.8 & 40 & 0.222 & 43.5 & 42.1 & 0.458 \\
\hline (range) & $\begin{array}{l}(19.8- \\
53.1)\end{array}$ & $\begin{array}{l}(24.9- \\
48.1)\end{array}$ & & $\begin{array}{l}(36.3- \\
53.1)\end{array}$ & $\begin{array}{l}(33.5- \\
44.6)\end{array}$ & & $\begin{array}{l}(19.8- \\
47.9)\end{array}$ & $\begin{array}{l}(24.9- \\
48.1) \\
\end{array}$ & \\
\hline $\begin{array}{c}\text { Histopathology } \\
\text { PDAC }\end{array}$ & $\begin{array}{c}25 \\
(37.3 \%)\end{array}$ & $\begin{array}{c}16 \\
(33.3 \%)\end{array}$ & 0.706 & $\begin{array}{c}19 \\
(44.2 \%)\end{array}$ & $\begin{array}{c}8 \\
(36.4 \%)\end{array}$ & 0.939 & $6(25 \%)$ & $\begin{array}{c}8 \\
(30.8 \%)\end{array}$ & 0.438 \\
\hline NET & $\begin{array}{c}9 \\
(13.4 \%)\end{array}$ & $\begin{array}{c}11 \\
(22.9 \%)\end{array}$ & & $\begin{array}{c}6 \\
(14.0 \%)\end{array}$ & $\begin{array}{c}3 \\
(13.6 \%)\end{array}$ & & $\begin{array}{c}3 \\
(12.5 \%)\end{array}$ & $\begin{array}{c}8 \\
(30.8 \%)\end{array}$ & \\
\hline $\begin{array}{l}\text { Other malign. TU, } \\
\text { MTS }\end{array}$ & $\begin{array}{c}9 \\
(13.4 \%)\end{array}$ & $\begin{array}{c}5 \\
(10.4 \%)\end{array}$ & & $\begin{array}{c}4 \\
(9.3 \%)\end{array}$ & $\begin{array}{c}4 \\
(18.2 \%)\end{array}$ & & $\begin{array}{c}5 \\
(20.9 \%)\end{array}$ & $\begin{array}{c}1 \\
(3.8 \%)\end{array}$ & \\
\hline Cystic tumours & $\begin{array}{c}17 \\
(25.4 \%)\end{array}$ & $\begin{array}{c}8 \\
(16.7 \%)\end{array}$ & & $\begin{array}{c}9 \\
(20.9 \%)\end{array}$ & $\begin{array}{c}2 \\
(9.1 \%)\end{array}$ & & $\begin{array}{c}8 \\
(33.3 \%)\end{array}$ & $\begin{array}{c}6 \\
(23.1 \%)\end{array}$ & \\
\hline Chronic pancreatitis & $\begin{array}{c}3 \\
(4.5 \%)\end{array}$ & $\begin{array}{c}5 \\
(10.4 \%)\end{array}$ & & $\begin{array}{c}3 \\
(6.9 \%)\end{array}$ & $\begin{array}{c}2 \\
(9.1 \%)\end{array}$ & & 0 & $\begin{array}{c}3 \\
(11.5 \%)\end{array}$ & \\
\hline $\begin{array}{l}\text { Other benign } \\
\text { conditions }\end{array}$ & $4(6 \%)$ & $\begin{array}{c}3 \\
(6.3 \%) \\
\end{array}$ & & $\begin{array}{c}2(4,7 \\
\%) \\
\end{array}$ & $\begin{array}{c}3(13,6 \\
\%)\end{array}$ & & $\begin{array}{c}2 \\
(8.3 \%) \\
\end{array}$ & 0 & \\
\hline Spleen preservation & $\begin{array}{c}10(14.9 \\
\%)\end{array}$ & $\begin{array}{c}6(12.5 \\
\%)\end{array}$ & 0.79 & $\begin{array}{c}8(18.6 \\
\%)\end{array}$ & $\begin{array}{c}4(18.2 \\
\%)\end{array}$ & 0.99 & $\begin{array}{c}2 \\
(8.3 \%)\end{array}$ & $\begin{array}{c}2 \\
(7.6 \%)\end{array}$ & 0.939 \\
\hline $\begin{array}{l}\text { Operative time } \\
\text { (min.); median }\end{array}$ & 180 & 210 & 0.037 & 168 & 210 & 0.07 & 195 & 210 & 0.336 \\
\hline (range) & $\begin{array}{l}(100- \\
390)\end{array}$ & $\begin{array}{l}(115- \\
380)\end{array}$ & & $\begin{array}{l}(100- \\
390)\end{array}$ & $\begin{array}{l}(120- \\
320)\end{array}$ & & $\begin{array}{l}(120- \\
325)\end{array}$ & $\begin{array}{l}(115- \\
380)\end{array}$ & \\
\hline $\begin{array}{l}\text { Blood loss (ml); } \\
\text { median (range) }\end{array}$ & 400 & 500 & 0.52 & 300 & 400 & 0.501 & 800 & 600 & 0.25 \\
\hline & $\begin{array}{c}(50- \\
3500)\end{array}$ & $\begin{array}{c}(50- \\
4000)\end{array}$ & & $\begin{array}{c}(50- \\
3000)\end{array}$ & $\begin{array}{c}(50- \\
3000)\end{array}$ & & $\begin{array}{l}(300- \\
3500)\end{array}$ & $\begin{array}{l}(100- \\
4000)\end{array}$ & \\
\hline Pancreatic thickness & 11 & 13 & 0.0496 & 10 & 10.5 & 0.16 & 15.5 & 16 & 0.327 \\
\hline $\begin{array}{l}(\mathrm{mm}) ; \text { median } \\
\text { (range) }\end{array}$ & $(6-30)$ & $(5-23)$ & & $(6-12)$ & $(5-12)$ & & $(13-30)$ & $(13-23)$ & \\
\hline $\begin{array}{c}\text { Transected in neck } \\
\text { (\%) }\end{array}$ & $\begin{array}{c}54 \\
(80.6 \%)\end{array}$ & $\begin{array}{c}32 \\
(66.7 \%)\end{array}$ & 0.13 & $61(9$ & $.8 \%)$ & & $25(50 \%$ & $<$ & 0001 \\
\hline Extended resections & $\begin{array}{c}13 \\
(19.4 \%)\end{array}$ & $\begin{array}{c}10 \\
(20.8 \%) \\
\end{array}$ & 0.848 & $\begin{array}{c}8 \\
(18.6 \%) \\
\end{array}$ & $\begin{array}{c}5 \\
(22.7 \%) \\
\end{array}$ & 0.698 & $\begin{array}{c}5 \\
(20.8 \%) \\
\end{array}$ & $\begin{array}{c}5 \\
(19.2 \%) \\
\end{array}$ & 0.893 \\
\hline
\end{tabular}

BMI, body mass index; PDAC, pancreatic ductal adenocarcinoma; NET, neuroendocrine tumour; TU, tumour; MTS, metastasis 
Table 2. Outcomes in general cohort and in sub-groups according to transection site thickness (thin pancreas transection site thickness lesser than $13 \mathrm{~mm}$, thick pancreas - equal or more than $13 \mathrm{~mm}$ )

\begin{tabular}{|c|c|c|c|c|c|c|c|c|c|}
\hline & \multicolumn{3}{|c|}{$\begin{array}{l}\text { OVERALL } \\
(\mathrm{n}=115)\end{array}$} & \multicolumn{3}{|c|}{$\begin{array}{l}\text { THIN PANCREAS } \\
(\mathrm{n}=65) \\
\end{array}$} & \multicolumn{3}{|c|}{$\begin{array}{c}\text { THICK PANCREAS } \\
(\mathrm{n}=50)\end{array}$} \\
\hline & $\begin{array}{l}\text { stapler } \\
(\mathrm{n}=67)\end{array}$ & $\begin{array}{l}\text { hand- } \\
\text { sewn } \\
(\mathrm{n}=48)\end{array}$ & $\bar{p}$ & $\begin{array}{l}\text { stapler } \\
(\mathrm{n}=43)\end{array}$ & $\begin{array}{l}\text { hand- } \\
\text { sewn } \\
(\mathrm{n}=22)\end{array}$ & $p$ & $\begin{array}{l}\text { stapler } \\
(\mathrm{n}=24)\end{array}$ & $\begin{array}{l}\text { hand- } \\
\text { sewn } \\
(\mathrm{n}=26)\end{array}$ & $p$ \\
\hline $\mathrm{BL}$ & $\begin{array}{c}8 \\
(11.9 \%)\end{array}$ & $\begin{array}{c}7 \\
(14.6 \%)\end{array}$ & 0.781 & $3(7 \%)$ & $\begin{array}{c}3 \\
(13.6 \%)\end{array}$ & 0.399 & $\begin{array}{c}5 \\
(20.8 \%)\end{array}$ & $\begin{array}{c}4 \\
(15.4 \%)\end{array}$ & 0.721 \\
\hline CR - POPF & $\begin{array}{c}20 \\
(29.9 \%)\end{array}$ & $\begin{array}{c}18 \\
(37.5 \%)\end{array}$ & 0.426 & $2(4.6 \%)$ & $\begin{array}{c}10 \\
(45.5 \%)\end{array}$ & 0.0002 & $\begin{array}{c}18 \\
(75 \%)\end{array}$ & $\begin{array}{c}8 \\
(30.8 \%)\end{array}$ & 0.0023 \\
\hline Gr. B & $\begin{array}{c}14 \\
(20.9 \%)\end{array}$ & $\begin{array}{c}11 \\
(22.9 \%)\end{array}$ & & $2(4.6 \%)$ & $\begin{array}{c}4 \\
(18.2 \%)\end{array}$ & & $\begin{array}{c}12 \\
(50 \%)\end{array}$ & $\begin{array}{c}6 \\
(23.1 \%)\end{array}$ & \\
\hline Gr. C & $6(9 \%)$ & $\begin{array}{c}7 \\
(14.6 \%) \\
\end{array}$ & 0.583 & 0 & $\begin{array}{c}6 \\
(27.3 \%) \\
\end{array}$ & 0.002 & 6 (25\%) & $2(7.7 \%)$ & 0.007 \\
\hline $\begin{array}{c}\text { 90-day } \\
\text { mortality }\end{array}$ & $1(1.5 \%)$ & $2(4.2 \%)$ & 0.446 & 0 & $2(9.1 \%)$ & 0.111 & $\begin{array}{c}1 \\
(4.2 \%)\end{array}$ & 0 & 0.48 \\
\hline $\begin{array}{l}\text { Overall } \\
\text { morbidity }\end{array}$ & $\begin{array}{c}40 \\
(59.7 \%)\end{array}$ & $\begin{array}{c}33 \\
(68.8 \%)\end{array}$ & 0.33 & $\begin{array}{c}16 \\
(37.2 \%)\end{array}$ & $\begin{array}{c}16 \\
(72.7 \%)\end{array}$ & 0.008 & $\begin{array}{c}24 \\
(100 \%)\end{array}$ & $\begin{array}{c}17 \\
(65.4 \%)\end{array}$ & 0.0012 \\
\hline $\begin{array}{c}\text { Clavien-Dindo } \geq \\
\text { IIIa }\end{array}$ & $\begin{array}{c}20 \\
(29.9 \%)\end{array}$ & $\begin{array}{c}16 \\
(33.3 \%)\end{array}$ & 0.695 & $\begin{array}{c}7 \\
\text { (16.3\%) }\end{array}$ & $\begin{array}{c}8 \\
(36.4 \%)\end{array}$ & 0.0859 & $\begin{array}{c}13 \\
(54.2 \%)\end{array}$ & $\begin{array}{c}8 \\
(30.8 \%)\end{array}$ & 0.107 \\
\hline SSI & $\begin{array}{c}10 \\
(14.9 \%)\end{array}$ & $\begin{array}{c}14 \\
(29.2 \%)\end{array}$ & 0.072 & $3(7 \%)$ & $\begin{array}{c}7 \\
(31.8 \%)\end{array}$ & 0.0152 & $\begin{array}{c}7 \\
(29.2 \%)\end{array}$ & $\begin{array}{c}7 \\
(26.9 \%)\end{array}$ & 0.866 \\
\hline $\begin{array}{c}\mathrm{Re}- \\
\text { laparotomy }\end{array}$ & $\begin{array}{c}10 \\
(14.9 \%)\end{array}$ & $\begin{array}{c}10 \\
(20.8 \%)\end{array}$ & 0.46 & $\begin{array}{c}5 \\
(11.6 \%)\end{array}$ & $\begin{array}{c}5 \\
(22.7 \%)\end{array}$ & 0.29 & $\begin{array}{c}5 \\
(20.8 \%)\end{array}$ & $\begin{array}{c}5 \\
(19.2 \%)\end{array}$ & 0.89 \\
\hline $\begin{array}{l}\text { LOS (days), } \\
\text { median } \\
\text { (range) }\end{array}$ & $\begin{array}{c}11 \\
(7-86)\end{array}$ & $\begin{array}{c}11,5 \\
(7-143)\end{array}$ & 0.331 & $\begin{array}{c}11 \\
(7-44)\end{array}$ & $\begin{array}{l}15 \\
(7-41)\end{array}$ & 0.032 & $\begin{array}{c}21 \\
(8-86)\end{array}$ & $\begin{array}{c}11 \\
(7-143)\end{array}$ & 0.009 \\
\hline
\end{tabular}

BL - biochemical leak; CR-POPF - clinically relevant postoperative pancreatic fistula grade B, C - according to ISGPS Definition [14]

SSI, surgical site infection; LOS, length of hospital stay;

Table 3. Univariate and multivariate analysis of pancreatic leak (CR-POPF or BL) - risk factors. 


\begin{tabular}{|c|c|c|c|c|}
\hline \multirow{2}{*}{} & \multicolumn{3}{|c|}{ UNIVARIATE } & \multicolumn{2}{c|}{ MULTIVARIATE } \\
\cline { 2 - 5 } & leak - OR (95\% CI) & $\mathrm{p}$ & leak - OR (95\% CI) & $\mathrm{p}$ \\
\hline BMI $\geq 30$ & $1.83(0.76-4.43)$ & 0.189 & $1.43(0.52-3.92)$ & 0.49 \\
PDAC & $0.64(0.29-1.39)$ & 0.33 & & \\
Splenectomy & $1.51(0.51-4.46)$ & 0.59 & & \\
Blood loss $\geq 2000 \mathrm{ml}$ & $2.93(0.86-10.3)$ & 0.11 & $2.24(0.65-7.79)$ & 0.2 \\
Extended pancreatectomy & $1.69(0.67-4.25)$ & 0.35 & & \\
Parenchyma $\geq 13 \mathrm{~mm}$ & $6.09(2.7-13.7)$ & $\mathrm{p}<0.0001$ & $3.85(1.26-11.8)$ & 0.018 \\
Transection beyond neck & $7.16(2.63-19.5)$ & $\mathrm{p}<0.0001$ & $1.17(0.34-4.04)$ & 0.81 \\
\hline
\end{tabular}

BMI, body mass index; PDAC, pancreatic ductal adenocarcinoma; OR, odds ratio; CI, confidence interval

\section{Figures}




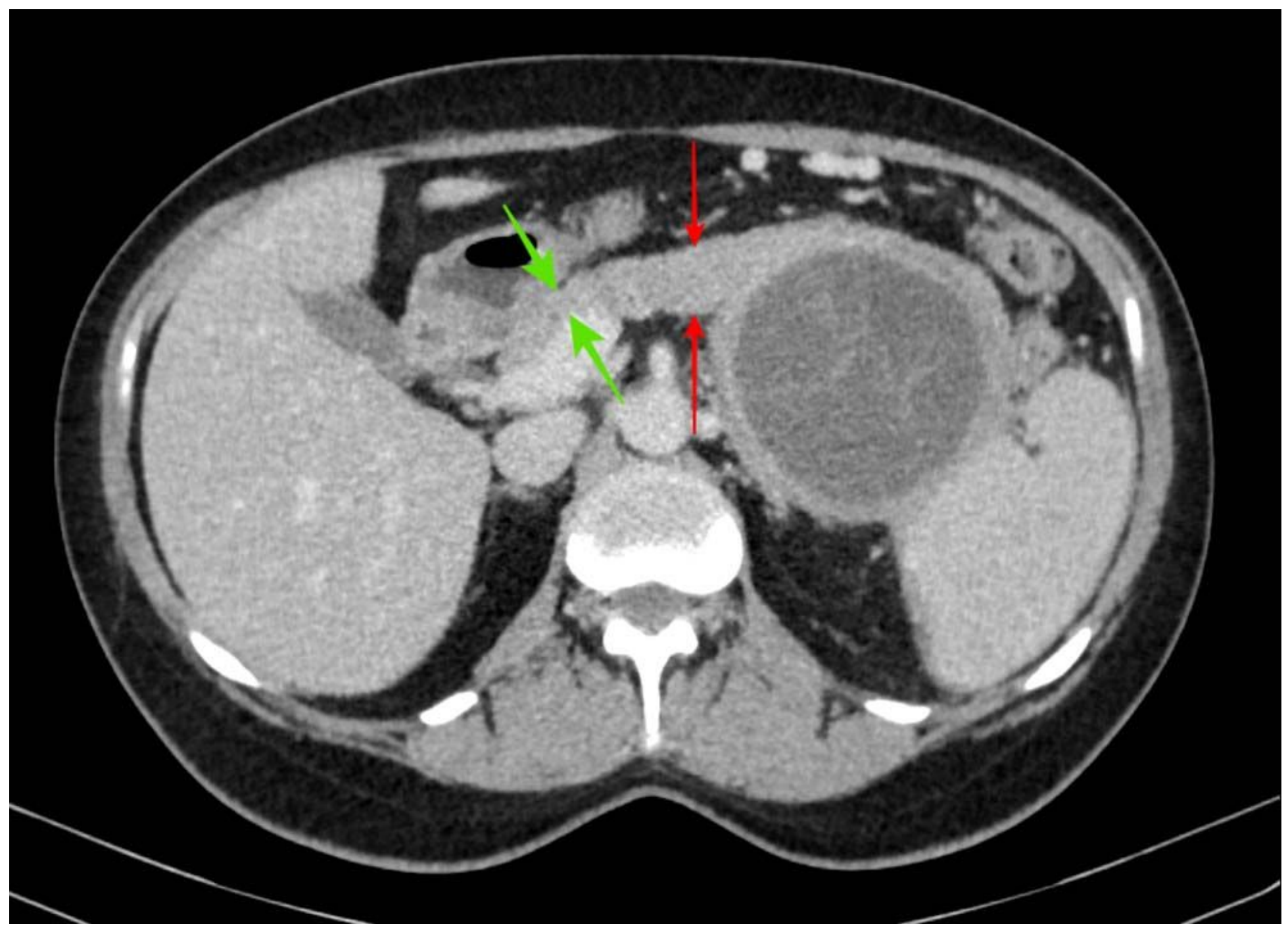

Figure 1

Anatomical determination of the pancreatic transection site and its thickness measurement 


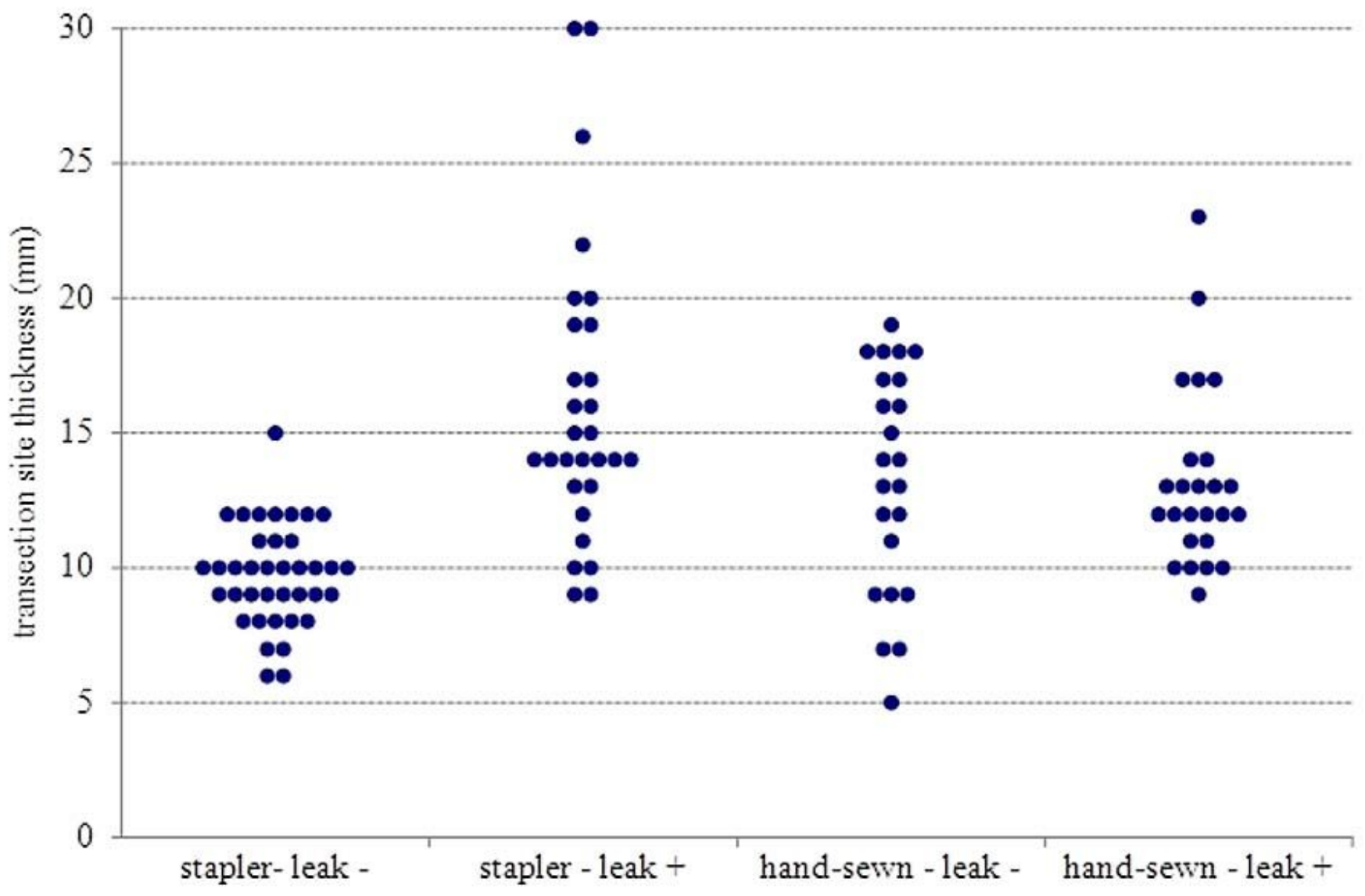

Figure 2

Distribution of transection site thickness according to stump closure and pancreatic leak (clinically relevant POPF or biochemical leak) occurrence 
A

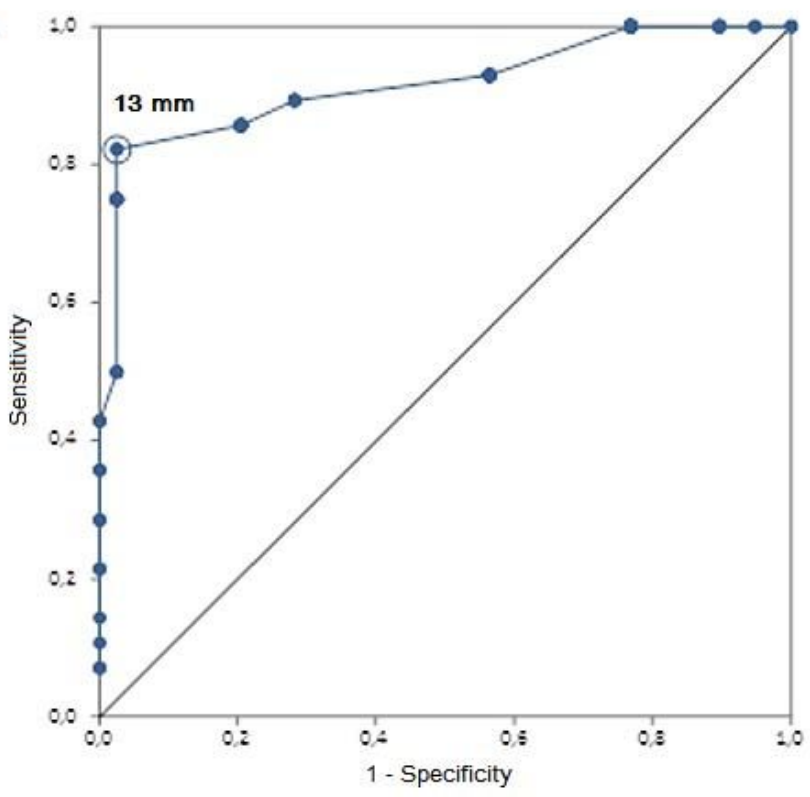

B

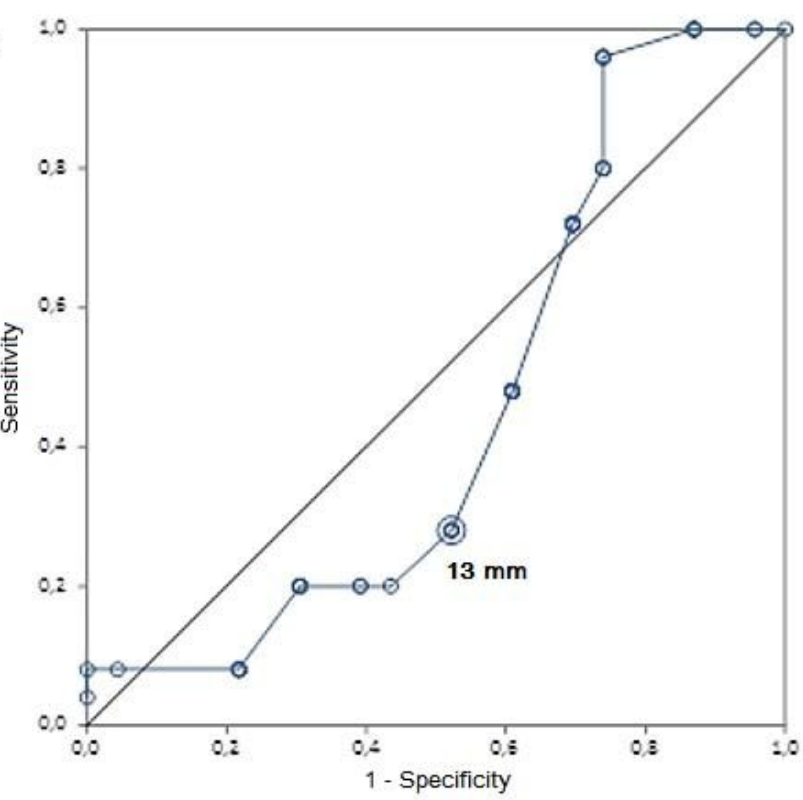

Figure 3

Receiver operating characteristic (ROC) curves of transection site thickness to predict pancreatic leak (clinically relevant POPF or biochemical leak) A - stapled stump closure - optimal cut-off $13 \mathrm{~mm}$; AUC 0,915 (95\% Cl 0,84 - 0,99), PPV 95,8\% (95\% Cl 78,9-99,9), NPV 88,4\% (95\% Cl 74,9-96,1) B - hand-sewn closure - optimal cut-off 13 mm; AUC 0,453 (95\% Cl 0,28 - 0,63), PPV 62,1\% (95\% Cl 42,3-79,3), NPV $63,2 \%(95 \% \mathrm{Cl} 38,4-83,7)$ AUC, area under the curve; PPV, positive predictive value; NPV, negative predictive valuate, $\mathrm{Cl}$, confidence interval. 